\title{
A Aplicação de Modelos Matemáticos em Situações-Problema Empresariais, com Uso do Software LI NDO
}

Márcia J ussara Hepp Rehfeldt

Orientador: Milton Antonio Zaro

Data da defesa: 15 de maio de 2009

Esta tese tem por objetivo mostrar a possibilidade de observação da existência da aprendizagem significativa a partir do uso de modelos matemáticos quando os alunos do curso de administração equacionam situações-problema empresariais com o auxílio do software LINDO. A pesquisa foi realizada com discentes do Centro Universitário UNIVATES, situado em Lajeado, Rio Grande do Sul, quando estes frequentaram a disciplina Pesquisa Operacional. Os fundamentos teóricos estão embasados na teoria da aprendizagem significativa de Ausubel $(1968,2003)$, na pesquisa operacional e suas ferramentas de resolução, principalmente o software LINDO, bem como na modelagem matemática. Metodologicamente, foram aplicados instrumentos de avaliação de subsunçores relacionados à capacidade de modelagem de problemas de programação linear. Face à ausência de alguns subsunçores, foram utilizados organizadores avançados que serviram como mecanismos pedagógicos para estabelecer relações entre aquilo que os alunos já sabiam e o que deveriam saber. Posteriormente, cada aluno desenvolveu, no mínimo, dois modelos matemáticos e dois mapas conceituais, sendo os primeiros no início da pesquisa e outros ao final. Como resultado, percebeu-se que o ambiente de modelagem matemática sugerido por Barbosa (2006) favoreceu a observação de aprendizagem significativa (AUSUBEL, 2003) da programação linear quando os alunos abstraíram e resolveram situações-problema empresariais com o auxílio do software LINDO. Os modelos matemáticos finais evoluíram, na maioria dos casos, apresentando mais variáveis e restrições. Por meio dos modelos matemáticos e mapas conceituais, foi possível observar algumas evidências em relação às exigências profissionais do administrador como a capacidade de reconhecer e de definir problemas e equacionar soluções e a capacidade de pensar estrategicamente e introduzir modificações no processo produtivo. Cabe ressaltar que os modelos matemáticos ilustram o conhecimento que o aluno possui. Por isso, são diferentes, têm níveis diferentes e refletem a idiossincrasia do processo ensino-aprendizagem, como postulam Moreira (2005) e Biembengut (2003).

Palavras-chave: Subsunçores. Modelagem matemática. Mapas conceituais. Alunos do curso de administração. Pesquisa operacional.

Referência: REHFELDT, Márcia Jussara Hepp. A Aplicação de Modelos Matemáticos em Situações-Problema Empresariais, com Uso do Software LINDO. Orientador: Milton Antonio Zaro. 2009. Tese (doutorado) - Programa de Pós-Graduação em Informática na Educação, Centro de Estudos Interdisciplinares em Novas Tecnologias da Educação, Universidade Federal do Rio Grande do Sul, 2009, Porto Alegre. 